\title{
Identification of Sarcocystis spp. in One-humped Camels (Camelus dromedarius) from Riyadh and Dammam, Saudi Arabia, via Histological and Phylogenetic Approaches
}

\author{
Dina M. Metwally ${ }^{1,2, *}$, , Tahani T. Al-Otaibi ${ }^{3}$, Isra M. Al-Turaiki ${ }^{4} \oplus$, Manal F. El-Khadragy $\left.{ }^{5,6} \mathbb{(}\right)$ \\ and Reem A. Alajmi ${ }^{1}$ \\ 1 Department of Zoology, College of Science, King Saud University, Riyadh 11451, KSA; ralajmi@ksu.edu.sa \\ 2 Department of Parasitology, Faculty of Veterinary Medicine, Zagazig University, Zagazig 44519, Egypt \\ 3 Department of Biology, Al-Nairiyah University College, University of Hafr Al-Batin, Hafr Al-Batin 31991, \\ Saudi Arabia; ttaalotaibi@gmail.com \\ 4 Department of Information Technology, College of Computer and Information Sciences, \\ King Saud University, Riyadh 11451, Saudi Arabia; ialturaiki@ksu.edu.sa \\ 5 Department of Biology, Faculty of Science, Princess Nourah Bint Abdelrahman University, Riyadh 84428, \\ Saudi Arabia; manalelkhadragy@yahoo.com \\ 6 Department of Zoology and Entomology, Faculty of Science, Helwan University, Cairo 11795, Egypt \\ * Correspondence: dhasanin@ksu.edu.sa
}

Received: 5 May 2020; Accepted: 22 June 2020; Published: 28 June 2020

Simple Summary: In the present work, we explored the existence of Sarcocystis spp. in samples of camels obtained from abattoirs in Riyadh, Saudi Arabia. We examined tissues of the tongue, heart, esophagus, diaphragm, and skeletal muscle by macroscopic assessments, optical microscopy of tissues, optical microscopy of digested sediment, Transmission Electron Microscopy (TEM), and Polymerase chain reaction (PCR) followed by gene sequencing. The results identified Sarcocystis cameli (S. cameli) and S. camelicanis. Sarcocystis spp. were detected in Saudi Arabian camels by molecular analysis. S. levinei and S. miescheriana were most closely related.

Abstract: Sarcocystis (S.) spp. are intracellular protozoan parasites that infect birds and animals, resulting in substantial commercial losses. Sarcocystis spp. have an indirect life cycle; canines and felines are known to act as final hosts, and numerous domestic and wild animals act as intermediate hosts. The presence of sarcocysts in camel meat may diminish its commercial quality. There is limited knowledge regarding the taxonomy and diagnosis of Sarcocystis spp. that infect camels in Saudi Arabia. In this study, transmission electron microscopy (TEM) revealed S. cameli and S. camelicanis (camelicanis) in Camelus (C.) dromedarius. This is the first report of S. camelicanis in Saudi Arabia and is considered a significant finding. Based on cytochrome c oxidase subunit I gene (COX1) sequences, two samples of Sarcocystis spp. isolated from C. dromedarius in Riyadh and Dammam were grouped with S. levinei hosted by Bubalus bubalis in India, S. rangi hosted by Rangifer tarandus in Norway, S. miescheriana hosted by Sus scrofa in Italy and S. fayeri hosted by Equus caballus in Canada. The sequences obtained in this study have been deposited in GenBank.

Keywords: Sarcocystis spp.; COX1; Camelus dromedarius

\section{Introduction}

Sarcocystis (S.) is a genus of intracellular coccidian parasites that was first identified in 1843 [1]. More than 200 species have been identified and were demonstrated to infect a wide range of domestic 
and wild animals, resulting in significant losses in farm animals worldwide [2,3]. Sarcocystis spp. accomplish their life cycles in two hosts, a final and an intermediate host, and are known to have a high level of host specificity with regard to their intermediate hosts as opposed to their final hosts [4]. The asexual stages of Sarcocystis development occur in intermediate hosts (herbivorous animals, such as sheep, cattle and camels, and primates, such as humans, poikilothermic animals and birds), where sarcocysts generally become visible in skeletal muscles and in the striated muscles of the heart, diaphragm and esophagus [5,6] but are rarely found in the smooth muscle of the intestine and the central nervous system [4-7]. The final hosts (e.g., canids, felids, marsupials and primates) become infected by eating intermediate host tissue infected with mature sarcocysts. Next, a stage of sexual reproduction occurs in the final host, after which oocysts/sporocysts are expelled into the environment through feces to be eaten by appropriate intermediate hosts.

The one-humped camel Camelus dromedarius is broadly distributed in the hot, arid regions of the Middle East, South Asia, Africa, the Canary Islands, and Central Australia. Compared to beef, lamb, and ostrich meat, camel meat is favored in several countries due to its reduced fat and cholesterol contents $[8,9]$. However, the presence of sarcocysts in camel meat may decrease its value for human utilization because camels act as intermediate hosts for at least two Sarcocystis spp.; furthermore, such infection is a general phenomenon in the one-humped camel due to its worldwide distribution [10-12]. The presence of sarcocysts in the musculature decreases the economic value of the musculature, especially if macroscopic cysts are detected, as their presence leads to condemning the product for consumption $[13,14]$. Microscopic cysts, on the other hand, may cause serious pathological conditions in infected animals, especially in the case of acute forms, and result in heavy production losses [15-17].

Infected camels generally exhibit subclinical infections, although Sarcocystis spp. can produce extensive pathology or death in these animals [12,18].

The diagnosis of acute sarcocystosis in camels is an onerous task because of the absence of an industrial standard indicator test, asymptomatic features of the infection, and the presence of microscopic sarcocysts. Muscle squash, pepsin digestion, trypsin digestion and histopathological examination have been used for the analysis of microscopic sarcocysts in camels $[11,12,18,19]$. Ultrastructural analysis of the cyst wall is quite useful in the identification of sarcocysts in camels. Transmission electron microscopy (TEM) has demonstrated that $S$. cameli has a primary cyst wall that appears as a thin wall with finger-like villar protrusions and rows of knob-like projections. S. ippeni was defined in Egypt [20], wherein the authors of that study observed cyst walls harboring cone-like villar protrusions. S. camelicanis was also defined in Egypt [19], wherein the authors found that the primary cyst wall appeared as a thick layer and had finger-like protrusions with a blunt apex. Furthermore, another study defined S. miescheri in Egypt [10], in which the primary cyst wall appeared as a thick electron-dense layer with spine-like protrusions.

Although molecular analysis might be an alternative technique for the identification of Sarcocystis spp., there is a limitation of such data for camels. The first molecular identification of S. cameli sarcocysts was performed in camels in Iran, wherein the 18S rRNA gene fragment was amplified from bradyzoite DNA using conventional polymerase chain reaction (PCR), followed by sequencing (GenBank: GU074011.1) and restriction fragment length polymorphism (RFLP) analysis [21,22]. However, the RFLP technique was found to be more expensive than DNA sequencing or electron microscopy techniques. In another study, the 18S rRNA gene was amplified from microscopic sarcocysts in camels, although no phylogenetic analysis was reported [12]. Therefore, in the present study, a molecular marker, cytochrome oxidase subunit I (COX1), was used to identify different Sarcocystis spp. infecting camels from Riyadh and Dammam, Saudi Arabia.

\section{Materials and Methods}

\subsection{Sample Collection}

Between February and October 2018, veterinarians collected samples of tissues (diaphragm, skeletal muscle, cardiac muscle, tongue, and esophagus) during postmortem investigations of slaughtered 
animals in the West Abattoir and Dammam Slaughterhouses in Riyadh and Dammam, Saudi Arabia, respectively. Tissue samples were collected from 37 (27 in Riyadh and 10 in Dammam) male camels aged $>5$ years and transported to the laboratory in boxes containing ice packs. This study (IRB number: KSU-SE-18-33) secured the approval of the Institutional Committee of Postgraduate Studies and Research at King Saud University (Saudi Arabia).

\subsection{Macroscopic Examination}

On the same day as the tissues were collected, a macroscopic analysis was performed. In this process, a scalpel was used to make as many as five transverse incisions on organs, such as the heart and the tongue, for the purpose of revealing the cysts (macroscopic). A macroscopic analysis of the entire esophagus was also performed to examine the external and internal walls; the lumen was exposed after longitudinal sectioning [23].

\subsection{Microscopic Examination}

Microscopic evaluation of cysts was performed using the squashing method [24]. Distinct fragments of each tissue with a thickness of approximately $5 \mathrm{~mm}$ were squashed robustly from both slides, after which an optical microscope was used to analyze the specimen. For all tissues, the procedure was performed in triplicate. Sarcocystis spp. were also examined by light microscopy and DNA analyses.

\subsection{Digestion Method}

For all tissues, approximately $20 \mathrm{~g}$ were minced before digestion for a period of $30 \mathrm{~min}$ in $100 \mathrm{~mL}$ at a temperature of $40{ }^{\circ} \mathrm{C}$; the digestion solution comprised pepsin $(1.3 \mathrm{~g}), \mathrm{HCl}(3.5 \mathrm{~mL})$ and $\mathrm{NaCl}$ $(2.5 \mathrm{~g})$ in distilled water $(500 \mathrm{~mL})$ [25]. After digestion, the mixture was centrifuged at $3500 \times \mathrm{g}$ for 3 min, followed by Giemsa staining and optical microscopy evaluation [26].

\subsection{Histopathological Examination}

Small specimens of muscles and organs were collected, fixed in 10\% neutral buffered formalin, serially dehydrated in increasing concentrations of ethanol (30\%,70\% and $95 \%$ absolute) and embedded in paraffin. Three 5- $\mu \mathrm{m}$-thick sections of each of the abovementioned organs and muscles were prepared, stained with hematoxylin and eosin and examined under an ECLIPSE NI-4 (Nikon, Tokyo, Japan) [27].

\subsection{Transmission Electron Microscopy (TEM)}

Six Sarcocystis spp. cysts embedded in the tissues were collected from organs, fixed in $0.1 \mathrm{M}$ sodium cacodylate buffer ( $\mathrm{pH} 7.4$ ) supplemented with $3 \%$ glutaraldehyde solution for $4 \mathrm{~h}$ at $4{ }^{\circ} \mathrm{C}$ and stored at $4{ }^{\circ} \mathrm{C}$ until processing. After fixation, the samples were washed in $0.1 \mathrm{M}$ sodium cacodylate buffer, fixed with $2 \%$ osmium tetroxide for $24 \mathrm{~h}$ and rewashed four to five times in the buffer (10-15 min each) [19]. The samples were serially dehydrated in increasing concentrations of acetone (30\%, 40\%, $50 \%, 70 \%, 90 \%$ and 100\%) and blocked with buffer supplemented with 1\% phosphotungstic acid and $1 \%$ uranyl acetate. Next, the $100 \%$ acetone solution was replaced with Polybed resin, followed by paraffin embedding and polymerization in an oven at $60{ }^{\circ} \mathrm{C}$ [28]. Moderately thin sections were prepared to observe Sarcocystis spp. cysts under a microscope (CX31, Olympus Corporation, Tokyo, Japan). Ultrathin sections were stained with uranyl acetate and lead citrate and examined using a JEM-1400 transmission electron microscope (JEOL, Tokyo, Japan) at $80 \mathrm{kV}$.

\subsection{Molecular Analysis}

\subsubsection{DNA Extraction and PCR Amplification}

From all the microscopic Sarcocystis isolates, six isolates were selected and washed five times in distilled water (sterile). gDNA from tissue was extracted using a DNA Mini Kit (QIAGEN GmbH, Hilden, Germany) (Cat. No. 51304) according to the manufacturer's instructions. Amplification of the 
COX1 gene was performed using the primer pairs mentioned in Table $1[28,29]$ and a thermocycler (Veriti ${ }^{\circledR}$ 96-well Thermal Cycler, Model 9902, Biosystem). This procedure was conducted in a mixture $(20 \mu \mathrm{L})$ containing $4 \mu \mathrm{L}$ of master mix $(5 \times), 12 \mu \mathrm{L}$ of RNase-free water and DNA template $(2 \mu \mathrm{L})$. The PCR program consisted of denaturation at $95^{\circ} \mathrm{C}$ for $5 \mathrm{~min}$, followed by 40 cycles of denaturation for $45 \mathrm{~s}$ at $95^{\circ} \mathrm{C}$, annealing for $45 \mathrm{~s}$ at $54{ }^{\circ} \mathrm{C}$ and extension for $10 \mathrm{~min}$ at $72{ }^{\circ} \mathrm{C}$. The PCR products were analyzed by $1.5 \%$ agarose gel electrophoresis.

Table 1. List of primers used for the amplification of cytochrome c oxidase subunit I (COX1) gene in Sarcocystis spp.

\begin{tabular}{|c|c|c|c|}
\hline Gene & Primers & Sequences & References \\
\hline \multirow{2}{*}{ COX1 } & SF1 & 5'-ATG GCG TAC AAC AAT CAT AAA GAA-3' & \multirow{2}{*}{ [28-30] } \\
\hline & SR9 & 5'-ATA TCC ATA CCR CCA TTG CCC AT-3' & \\
\hline
\end{tabular}

\subsubsection{DNA Sequencing}

The aforementioned PCR products were first purified and then sequenced in the reverse and forward directions (only) using a Genetic Analyzer at the Central Laboratory of King Saud University.

The sequences were analyzed using Geneious Prime Build [31]. All sequences were truncated slightly using the error probability method with a limit of 0.05 at both ends. A Basic Local Alignment Search Tool (BLAST) search was performed to identify related sequences. Multiple sequence alignments were generated using CLUSTAL Omega [32]. The maximum likelihood trees were constructed using PhyML 3.3 with 100 bootstraps [33].

\subsection{Statistical Analysis}

Statistical analysis was performed using the Statistical Package for Social Sciences (SPSS) software (version 17, SPSS, Inc., Chicago, IL, USA). The lengths and widths of at least five cysts from each organ (diaphragm, skeletal muscle, cardiac muscle, tongue, and esophagus) were determined by light microscopy and expressed as the mean sizes and amplitudes of variation.

\section{Results}

\subsection{Macroscopic Examination}

No macroscopic cysts were detected by the naked eye during the inspection of carcasses or collected samples.

\subsection{Microscopic Examination}

A compression technique with a light microscope was used for microscopic examination, in which 15 of 37 slaughtered camels $(40.54 \%)$ were found to be positive for microscopic cysts. In particular, the numbers of positive cases for diaphragm, skeletal muscle, cardiac muscle, tongue, and esophagus samples were $14 / 37(37.83 \%), 10 / 37(27.01 \%), 9 / 37(24.32 \%), 8 / 37(21.62 \%)$, and $3 / 37(8.10 \%)$, respectively. Thin-walled sarcocysts and thick-walled sarcocysts were observed. In contrast to the tissue squash method, the pepsin-hydrochloric acid digestion technique revealed a greater number of animals that were positive.

\subsubsection{Thin-Walled Microscopic Sarcocysts}

Unstained sarcocysts were found to have thin walls, to be elongated and spindle-like in shape, and to be present within the muscle fibers. The sarcocysts measured 197.9-405.6 $\mu \mathrm{m}$ in length (mean $301.75 \mu \mathrm{m}$ ) and 57.3-125.6 $\mu \mathrm{m}$ in breadth (mean $91.45 \mu \mathrm{m}$ ) (Figure 1A). Stained sarcocysts are shown in Figure 1B. Histopathological sections revealed that the cysts measured $83.50-135.50 \mu \mathrm{m}$ in length (mean $109.5 \mu \mathrm{m}$ ). The cyst wall consisted of two layers, an outer striated layer and an inner homogenous 
layer. The cystic cavity was divided into several compartments by fine trabeculae originating from the cyst wall (Figure 1C). Ultrastructural analysis of the cyst wall showed that $S$. cameli sarcocysts (shown in Figure 1D) have an outer cyst wall (Ocw) that is in close contact with the cyst wall, ground substance, metrocytes, and bradyzoites or merozoites. The primary cyst wall (Pcw) displayed irregular folded nonbranched finger-like villar protrusions with fibrillar elements originating from the ground substance at a distance of $0.54 \mu \mathrm{m}$ below the primary cyst wall and protruding into it. The villar protrusions measured $0.93 \mu \mathrm{m}$ in length and $0.77 \mu \mathrm{m}$ in width at the base and $0.35 \mu \mathrm{m}$ at the apex. The distance between each villar protrusion measured $1.7 \mu \mathrm{m}$. The finger-like process (Flp) was generally surrounded by numerous scattered host cell mitochondria. The ground substance was located directly under the primary cyst wall with a diameter of 1.27-1.7 $\mu \mathrm{m}$ (mean: $1.48 \mu \mathrm{m}$ ). The space between the primary cyst wall (Pcw) and the contents of the cyst was primarily fine, showing dense homogenous granules and fibrillar elements folding into the primary cyst wall. The ground substance extended into the interior of the cyst, forming a thin septum separating the entire cyst into compartments enclosing the metrocytes and bradyzoites or merozoites.

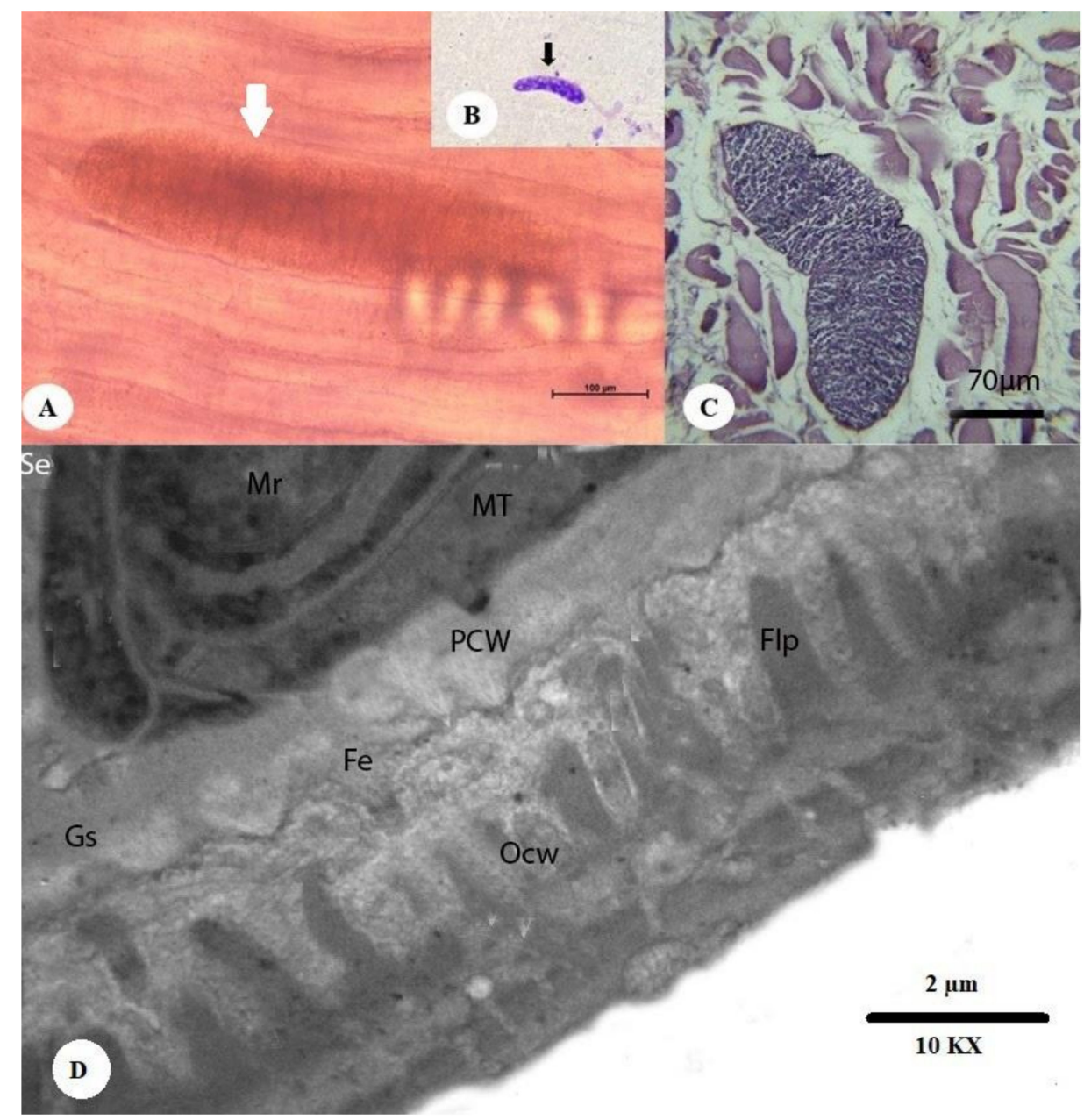

Figure 1. Morphology of a sarcocyst of $S$. cameli from the esophageal muscles of a camel (Camelus dromedarius). (A) Microscopic thin-walled S. cameli (white arrow) (bar $=100 \mu \mathrm{m})$. (B) Cysts stained with Giemsa after pepsin-hydrochloric acid digestion (black arrow). (C) Histopathological section of camel esophageal muscles showing the thin cyst wall $(\mathrm{CW})$ of $S$. cameli $(\mathrm{H} \& \mathrm{E})(\mathrm{bar}=70 \mu \mathrm{m})$. The thin and smooth cyst wall and the clearly visible septum are shown. (D) The cyst wall in detail, containing an outer cyst wall (Ocw), a primary cyst wall (Pcw), ground substance (Gs), septae (Se), merozoites $(\mathrm{Mr})$, fibrillar elements $(\mathrm{Fe})$, metrocytes $(\mathrm{Mt})$, and finger-like process (Flp) $(10,000 \times)$. 


\subsubsection{Thick-walled Microscopic Sarcocysts}

The sarcocysts appeared fusiform or spindle-shaped, measuring 151-449 $\mu \mathrm{m}$ in length (mean $300 \mu \mathrm{m}$ ) and 65-140 $\mu \mathrm{m}$ in breadth (mean $102.5 \mu \mathrm{m}$ ) (Figure 2A). Cysts after pepsin-hydrochloric acid digestion are depicted in Figure 2B. Histopathological sections demonstrated that the cysts had a thick wall composed of two layers: an outer striated layer and an inner smooth layer. The cyst cavity was divided into compartments by a narrow septum originating from the wall in the periphery of the cyst (Figure 2C). Ultrastructural analysis (Figure 1D) of the cyst wall revealed an outer cyst wall connected to the primary cyst wall (Pcw), ground substance (Gs), metrocytes, and bradyzoites for S. camelicanis.

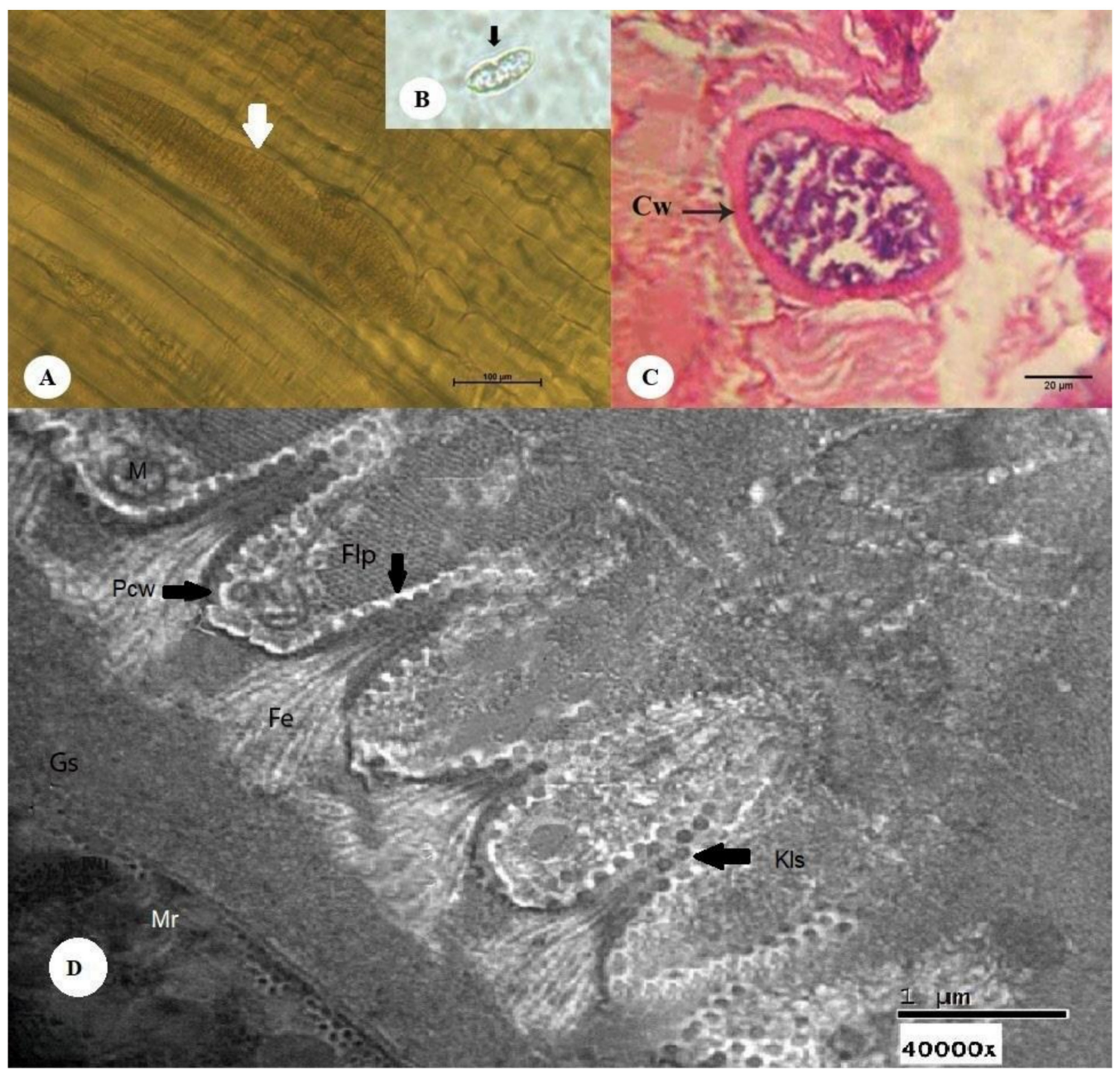

Figure 2. Morphology of a sarcocyst of S. camelicanis from the skeletal muscles of a camel (Camelus dromedarius). (A) Microscopic thick-walled S. camelicanis (white arrow) (bar $=100 \mu \mathrm{m}$ ). (B) Cysts after pepsin-hydrochloric acid digestion (small black arrow). (C) A histopathological section of the skeletal muscles of a camel shows the thick cyst wall $(\mathrm{Cw})$ (black arrow) of S. camelicanis and a clearly visible septum $(\mathrm{H} \& \mathrm{E}$; bar $=20 \mu \mathrm{m})$. (D) A Sarcocystis camelicanis thick-walled cyst showing the primary cyst wall (Pcw) (black arrow), ground substance (Gs), fibrillar elements (Fe), finger-like process (Flp), knoblike structures (Kls) (black arrow), Mitochondria (M), and merozoites (Mr) (40,000×). 
The primary cyst wall (Pcw) is a thick, dense layer adjacent to the Gs. Fibrillar elements (Fe) originating from the Gs at $0.60 \mu \mathrm{m}$ below the Pcw aggregated towards the Pcw and embedded into it, forming finger-like protrusions (Flp). The cyst measured 2.15-2.91 $\mu \mathrm{m}$ (mean $2.53 \mu \mathrm{m}$ ) in length and $0.52-0.60 \mu \mathrm{m}$ (mean $0.56 \mu \mathrm{m}$ ) in breadth. Each Flp carried characteristic multiple numerous knob-like structures (Kls), which were spherical in shape with a diameter of $0.10-0.14 \mu \mathrm{m}$ (mean $0.12 \mu \mathrm{m}$ ); their number varied from 19 to 25 on each protrusion. The distance between each Flp was $0.71-0.89 \mu \mathrm{m}$ (mean $0.80 \mu \mathrm{m}$ ), and they were generally surrounded by numerous dispersed host cell mitochondria (M). The Gs was found to be 1.25-1.60 $\mu \mathrm{m}$ (mean $1.42 \mu \mathrm{m}$ ) below the Pcw and in between the Pcw and metrocytes. It appeared as a homogeneous substance and extended to the interior of the cyst by a septum separating the entire cyst into a number of compartments enclosing the metrocytes, merozoites and other structures.

\subsection{Genetic Characteristics}

Genomic DNA extracted from four Sarcocystis spp. isolates, D7S (thin-walled cyst), D10S (thick-walled cyst), R10C (thick-walled cyst) and R16C (thin-walled cyst), were used for the amplification of 1000-bp COX1 sequences.

The first two were isolated from the skeletal muscle of a Dammam camel, and the last two were isolated from the cardiac muscle of a Riyadh camel. These sequences were 692, 513, 194, and 205 nucleotides in length, respectively, and shared a pairwise identity of $63.1 \%$. All sequences obtained in this study have been deposited in GenBank under accession numbers MK948444 (D7S), MK948443 (D10S), MK948442 (R10C), and MK948441 (R16C).

BLAST results showed that the D7S sequence had similarity to S. levinei hosted by Bubalus bubalis (heart tissue) in India, accession numbers MH255774-MH255777, with 86.5\% pairwise identity and $89.6 \%$ coverage. The D7S sequence also displayed similarity to $S$. rangi hosted by Rangifer tarandus in Norway, accession numbers KC209662-KC209666, with $85.2 \%$ pairwise identity and $87.57 \%$ coverage.

Furthermore, the D10S sequence exhibited similarity to $S$. miescheriana, accession number MH404202, hosted by Sus scrofa in Italy, with $80.7 \%$ pairwise identity and $43 \%$ coverage. The D10S sequence was also similar to $S$. fayeri, accession number LC171854, hosted by Equus caballus in Canada, with $79.1 \%$ pairwise identity and $43 \%$ coverage. The phylogenetic tree with bootstrap proportions is illustrated in Figure 3. Toxoplasma gondii (JX473253) was used as an outgroup. For R10C and R16C, ' 194 and 205' are very short sequences inappropriate for analysis. The tree shows that MK948444 (D7S) and MK948442 (R10C) are placed in a clade with S. levinei. MK948443 (D10S) is grouped with Sarcocystis miescheriana. MK948441 (R16C) is grouped with Sarcocystis fayeri. 


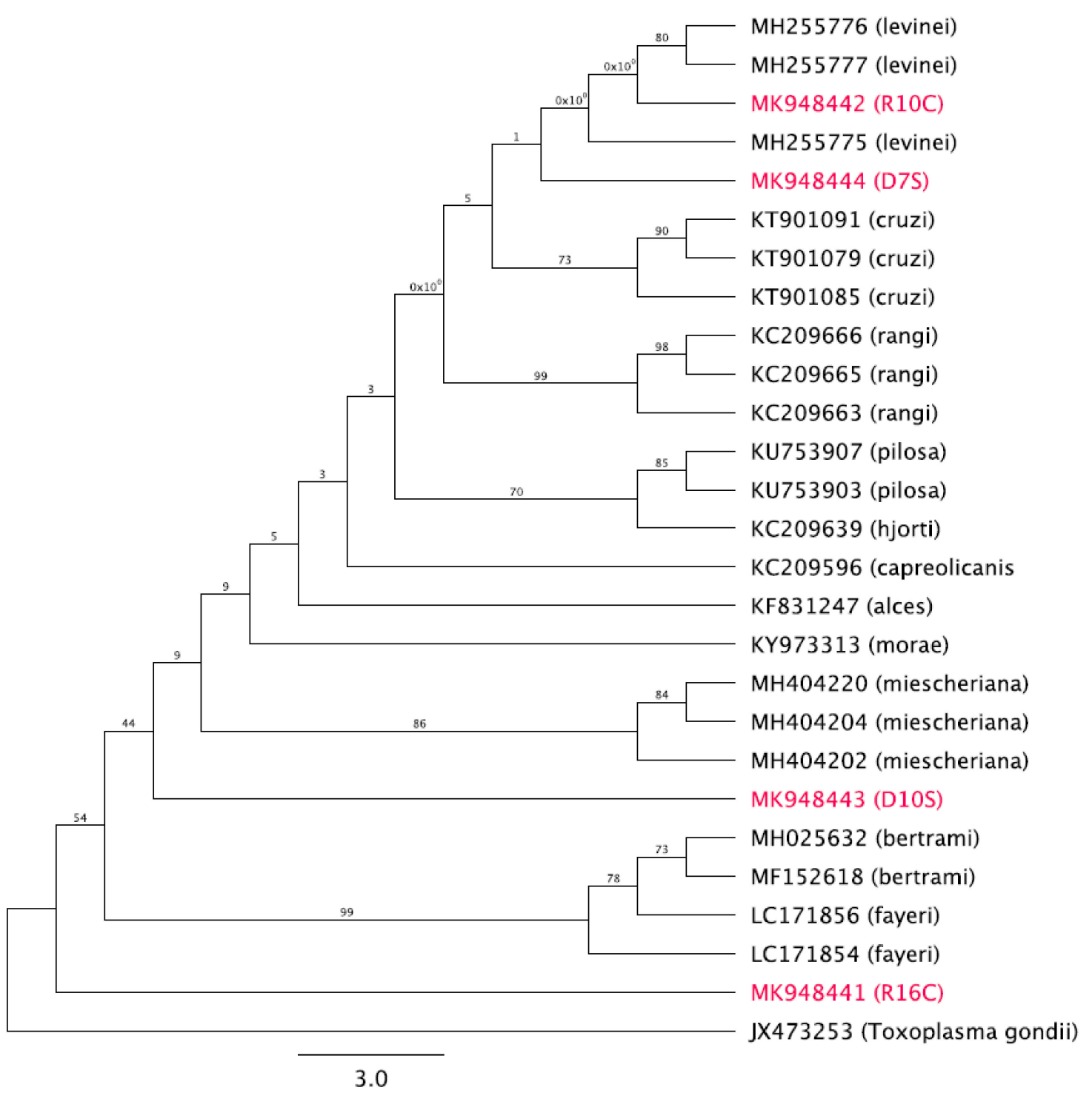

Figure 3. Genetic relationships of our samples isolated from camels in Saudi Arabia (highlighted in pink) with other Sarcocystis spp. retrieved from GenBank based on the COX1 region.

\section{Discussion}

To establish the occurrence of Sarcocystis spp., this study examined the esophagus, tongue, diaphragm, skeletal muscle, and heart tissue from 37 camel specimens (27 from Riyadh and 10 from Dammam). The results showed that the overall prevalence rates of Sarcocystis spp. were $40.74 \%$ (11/27) in Riyadh specimens and 40\% (4/10) in Dammam specimens.

In the present study, macroscopic cysts were not detected. However, macroscopic cysts have been reported to be less common in some esophageal samples [34,35]. In this study, the squashing and pepsin-hydrochloric acid digestion methods accompanied by light microscopy were used, wherein the technique of pepsin-hydrochloric acid digestion revealed a greater number of positive animals. Cysts from esophageal and skeletal muscle samples appeared in a cylindrical and spindle-like shape.

Cysts were found to have thin and smooth or thick walls divided internally into several compartments by trabeculae. Thin-walled cysts have been identified in the esophagus and diaphragm of camels slaughtered at Al-Ahsa Abattoir, Saudi Arabia [36]; in the esophagus, diaphragm, heart, shoulder, and masseter muscles of one-humped camels slaughtered in southern Ethiopia [37]; in the 
esophagus, diaphragm, heart, skeletal muscles, and tongue of one-humped camels slaughtered in Iran [18], and in the esophagus of one-humped camels slaughtered in Egypt [38].

Thick-walled cysts were found in the esophagus of one-humped camels slaughtered in Egypt [10]; in the esophagus, diaphragm, heart, skeletal muscles, and tongue of one-humped camels slaughtered in Egypt [19]; in the esophagus of one-humped camels slaughtered in Egypt [39], and in the esophagus, skeletal muscles, and tongue of one-humped camels slaughtered in Egypt [40]. Similarly, both thinand thick-walled Sarcocystis cysts have been suggested to be at different stages in the same parasite and have been termed S. cameli [41]. In addition, thick-walled cysts were found repeatedly and termed S. cameli, whereas thin-walled cysts were unnamed [18,25,36].

Sarcocystis spp. isolated from C. dromedarius from Dammam and Riyadh grouped alongside S. levinei hosted by B. bubalis (heart tissue) in India (accession numbers MH255774-MH255777) [42], S. rangi hosted by R. tarandus in Norway (accession numbers KC209662-KC209666) [43], S. miescheriana hosted by S. scrofa in Italy (accession number MH404202) [44], and S. fayeri hosted by E. caballus in Canada (accession number LC171854) [45].

In the present study, four partial sequences of the COX1 gene were analyzed. Two samples, R10C (thick-walled cyst) and D7S (thin-walled cyst), isolated from C. dromedarius in Riyadh and Dammam, Saudi Arabia, respectively, were identified by histological and TEM approaches as Sarcocystis spp. The phylogenetic tree shows that these two samples are related to $S$. mansoni hosted by South American camelids, S. levinei hosted by water buffaloes, and S. miescheriana hosted by pigs, suggesting that camels are receptors of Sarcocystis spp. from other intermediate hosts.

The main limitation of this study lies in the other two samples, D10S and R16C. These two samples were identified by histological and TEM approaches as Sarcocystis spp. (D10S, thick-walled cyst; and R16C, thin-walled cyst). However, in the phylogenetic tree, they were not grouped in a clade with R10C and D7S. Through a deeper analysis of the raw data, it was found that the samples were of lower quality than R10C and D7S. This low quality affected the process of phylogenetic tree construction.

\section{Conclusions}

In this study, our results highlight the necessity to reinforce a more in-depth phylogenetic analysis and identification of Sarcocystis spp. with more taxa and different molecular markers. For instance, amplification of the 18S rRNA gene should be performed to further distinguish among the closely related Sarcocystis spp.

Author Contributions: Conceptualization: D.M.M. Data curation: I.M.A.-T. Formal analysis: T.T.A.-O. Funding acquisition: D.M.M. Investigation: D.M.M. and T.T.A.-O. Methodology: T.T.A.-O. Project administration: D.M.M. and R.A.A. Resources: T.T.A.-O. and M.F.E.-K. Software: I.M.A.-T. Supervision: D.M.M. and R.A.A. Validation: D.M.M. Visualization: M.F.E.-K. Writing: original draft: D.M.M. Writing, reviewing and editing: D.M.M., R.A.A., M.F.E.-K., T.T.A.-O. and I.M.A.-T. All authors have read and agreed to the published version of the manuscript.

Funding: The authors extend their appreciation to the Deanship of Scientific Research at King Saud University for funding this work through research group No. RG-1441-381.

Conflicts of Interest: The authors declare no conflict of interest. The funders had no role in the design of the study; in the collection, analyses, or interpretation of data; in the writing of the manuscript, or in the decision to publish the results

\section{References}

1. Miescher, F. Über eigenthümliche Schläuche in den Muskeln einer Hausmaus. Ber. Verhandl Nat. Gesell Basel 1843, 5, 198-202.

2. Tenter, A.M. Current research on Sarcocystis species of domestic animals. Int. J. Parasitol. 1995, 25, 1311-1330. [CrossRef]

3. Dubey, J. Foodborne and waterborne zoonotic sarcocystosis. Food Waterborne Parasitol. 2015, 1, 2-11. [CrossRef]

4. Fayer, R. Sarcocystis spp. Human Infections. Clin. Microbiol. Rev. 2004, 17, 894-902. [CrossRef] 
5. Hidron, A.; Vogenthaler, N.; Santos-Preciado, J.I.; Rodriguez-Morales, A.J.; Franco-Paredes, C.; Rassi, A. Cardiac Involvement with Parasitic Infections. Clin. Microbiol. Rev. 2010, 23, 324-349. [CrossRef]

6. Dubey, J.P.; Calero-Bernal, R.; Rosenthal, B.M.; Speer, C.A.; Fayer, R. Sarcocystosis of Animals and Humans; CRC Press: Boca Raton, FL, USA, 2015.

7. Miller, M.; Barr, B.; Nordhausen, R.; James, E.; Magargal, S.; Murray, M.; Conrad, P.; Toy-Choutka, S.; Jessup, D.; Grigg, M. Ultrastructural and molecular confirmation of the development of Sarcocystis neurona tissue cysts in the central nervous system of southern sea otters (Enhydra lutris nereis). Int. J. Parasitol. 2009, 39, 1363-1372. [CrossRef]

8. Kadim, I.; Mahgoub, O.; Purchas, R. A review of the growth, and of the carcass and meat quality characteristics of the one-humped camel (Camelus dromedaries). Meat Sci. 2008, 80, 555-569. [CrossRef] [PubMed]

9. Kadim, I.T.; Mahgoub, O.; Mbaga, M. Potential of camel meat as a non-traditional high quality source of protein for human consumption. Anim. Front. 2014, 4, 13-17. [CrossRef]

10. Mandour, A.M.; Rabie, S.A.; Mohammed, N.; Hussein, N.M. On the presence of Sarcocystis miescheri sp. nov. in camels of Qena Governorate. Egypt. Acad. J. Boil. Sci. E. Med Èntomol. Parasitol. 2011, 3, 1-7. [CrossRef]

11. Hamidinejat, H.; Hekmatimoghaddam, S.; Jafari, H.; Sazmand, A.; Molayan, P.H.; Derakhshan, L.; Mirabdollahi, S. Prevalence and distribution patterns of Sarcocystis in camels (Camelus dromedarius) in Yazd province, Iran. J. Parasit. Dis. 2012, 37, 163-165. [CrossRef]

12. Omer, S.A.; Alzuraiq, A.A.; Mohammed, O.B. Prevalence and molecular detection of Sarcocystis spp. infection in the dromedary camel (Camelus dromedarius) in Riyadh city, Saudi Arabia. Biomed. Res. 2017, 28, 4962-4965.

13. Oryan, A.; Moghaddar, N.; Gaur, S.N. The distribution pattern of Sarcocystis species, their transmission and pathogenesis in sheep in Fars Province of Iran. Veter. Res. Commun. 1996, 20, 243-253. [CrossRef]

14. Dubey, J.P.; Lindsay, D.S.; Speer, C.A.; Fayer, R.; Livingston, C.W. Sarcocystis arieticanis and Other Sarcocystis Species in Sheep in the United States. J. Parasitol. 1988, 74, 1033. [CrossRef]

15. Fayer, R. Economic losses to Sarcocystis. Natl. Wool. Grow. 1976, 66, 22-28.

16. Munday, B. The effect of Sarcocystis ovicanis on growth rate and haematocrit in lambs. Veter. Parasitol. 1979, 5, 129-135. [CrossRef]

17. Munday, B. Effects of different doses of dog-derived Sarcocystis sporocysts on growth rate and haematocrit in lambs. Veter. Parasitol. 1986, 21, 21-24. [CrossRef]

18. Valinezhad, A.; Oryan, A.; Ahmadi, N. Sarcocystis and Its Complications in Camels (Camelus dromedarius) of Eastern Provinces of Iran. Korean J. Parasitol. 2008, 46, 229-234. [CrossRef]

19. Abdel-Ghaffar, F.; Mehlhorn, H.; Bashtar, A.-R.; Al-Rasheid, K.; Sakran, T.; El-Fayoumi, H. Life cycle of Sarcocystis camelicanis infecting the camel (Camelus dromedarius) and the dog (Canis familiaris), light and electron microscopic study. Parasitol. Res. 2009, 106, 189-195. [CrossRef]

20. Entzeroth, R.; A Ghaffar, F.; Chobotar, B.; Scholtyseck, E. Fine structural study of Sarcocystis sp. from Egyptian camels (Camelus dromed arius). Acta Veter. Acad. Sci. Hung. 1981, 29, 335-339.

21. Motamedi, G.R.; Dalimi, A.; Nouri, A.; Aghaeipour, K. Ultrastructural and molecular characterization of Sarcocystis isolated from camel (Camelus dromedarius) in Iran. Parasitol. Res. 2010, 108, 949-954. [CrossRef] [PubMed]

22. Eslampanah, M.; Motamedi, G.R.; Dalimi, A.; Noori, A.; Habibi, G.R.; Aghaeepour, K.; Niroumand, M. Study of camel and goat Sarcocystis by electron microscopic and PCR-RFLP. Vet. Res. Biol. Prod. 2016, 29, 77-84.

23. Bittencourt, M.V.; Meneses, I.D.S.; Ribeiro-Andrade, M.; De Jesus, R.F.; De Araújo, F.R.; Gondim, L.F. Sarcocystis spp. in sheep and goats: Frequency of infection and species identification by morphological, ultrastructural, and molecular tests in Bahia, Brazil. Parasitol. Res. 2016, 115, 1683-1689. [CrossRef] [PubMed]

24. Odening, K.; Stolte, M.; Bockhardt, I. On the diagnostics of Sarcocystis in cattle: Sarcocysts of a species unusual for Bos taurus in a dwarf zebu. Veter. Parasitol. 1996, 66, 19-24. [CrossRef]

25. Dubey, J.; Speer, C.; Charleston, W. Ultrastructural differentiation between sarcocysts of Sarcocystis hirsuta and Sarcocystis hominis. Veter. Parasitol. 1989, 34, 153-157. [CrossRef]

26. Hamidinejat, H.; Moetamedi, H.; Alborzi, A.; Hatami, A. Molecular detection of Sarcocystis species in slaughtered sheep by PCR-RFLP from south-western of Iran. J. Parasit. Dis. 2013, 38, 233-237. [CrossRef]

27. Carleton, H.M. Histological Technique for Normal and Pathological Tissues and the Identification of Parasites, 3rd ed.; Oxford University Press: London, UK, 1957. 
28. Gjerde, B. Phylogenetic relationships among Sarcocystis species in cervids, cattle and sheep inferred from the mitochondrial cytochrome c oxidase subunit I gene. Int. J. Parasitol. 2013, 43, 579-591. [CrossRef]

29. Gjerde, B. Sarcocystis species in red deer revisited: With a re-description of two known species as Sarcocystis elongata n. sp. and Sarcocystis truncata n. sp. based on mitochondrial cox1 sequences. Parasitology 2013, 141, 441-452. [CrossRef]

30. Metwally, D.M.; Al-Damigh, M.A.; Al-Turaiki, I.; El-Khadragy, M.F. Molecular Characterization of Sarcocystis Species Isolated from Sheep and Goats in Riyadh, Saudi Arabia. Animals 2019, 9, 256. [CrossRef] [PubMed]

31. Geneious Prime. Available online: http://www.geneious.com/ (accessed on 7 April 2020).

32. Sievers, F.; Wilm, A.; Dineen, D.; Gibson, T.J.; Karplus, K.; Li, W.; López, R.; McWilliam, H.; Remmert, M.; Soeding, J.; et al. Fast, scalable generation of high-quality protein multiple sequence alignments using Clustal Omega. Mol. Syst. Boil. 2011, 7, 539. [CrossRef] [PubMed]

33. Guindon, S.; Lefort, V.; Anisimova, M.; Hordijk, W.; Gascuel, O.; Dufayard, J.-F. New Algorithms and Methods to Estimate Maximum-Likelihood Phylogenies: Assessing the Performance of PhyML 3.0. Syst. Boil. 2010, 59, 307-321. [CrossRef] [PubMed]

34. Wahba, A.A. Morphobiological Studies on Cryptosporidia and Sarcocystis in Animals and Their Impact on Their Health. Ph.D. Thesis, Faculty of Veterinary Medicine, Zagazig University, Zagazig, Egypt, 1994.

35. Fatani, A.; Hilali, M.A.; Al-Atiya, S.; Al-Shami, S. Prevalence of Sarcocystis in camels (Camelus dromedarius) from Al-Ahsa, Saudi Arabia. Veter. Parasitol. 1996, 62, 241-245. [CrossRef]

36. Al-Quraishy, S.A.; Bashtar, A.R.; Al-Rasheid, K.; Abdel-Ghaffar, F. Prevalence and ultrastructure of Sarcocystis species infecting camels (Camelus dromedarius) slaughtered in Riyadh city Saudi Arabia. Saudi J. Biol. Sci. 2004, 11, 135-141.

37. Woldemeskel, M.; Gumi, B. Prevalence of sarcocysts in one-humped camel (Camelus dromedarius) from Southern Ethiopia. J. Vet. Med. Ser. B 2001, 48, 223-226. [CrossRef] [PubMed]

38. Hilali, M.; Mohamed, A. The dog (Canis familiaris) as the final host of Sarcocystis cameli (Mason, 1910). Trop. Parasitol. 1980, 31, 213-214.

39. Abd-Elmalek, B.S.; Abed, G.H.; Mandour, A.M. Study on Sarcosystis sp. By Light and Electron Microscopy in Camel Muscles at Assiut Governorate. J. Veter. Sci. Technol. 2015, 6. [CrossRef]

40. Mason, F.E. Sarcocysts in the camel in Egypt. J. Comp. Pathol. Ther. 1910, 23, 168-176. [CrossRef]

41. Moré, G.; Regensburger, C.; Gos, M.L.; Pardini, L.; Verma, S.K.; Ctibor, J.; Serrano-Martínez, E.; Dubey, J.P.; Venturini, M.C. Sarcocystis masoni, n sp. (Apicomplexa: Sarcocystidae), and redescription of Sarcocystis aucheniae from llama (Lama glama), guanaco (Lama guanicoe) and alpaca (Vicugna pacos). Parasitology 2016, 143, 617-626.

42. Singh, D.; Kumar, B. UP Pandit Deen Dayal Upadhyaya Pashu-Chikitsa Vigyan Vishwavidyalaya Evam Go Anusandhan Sansthan. Ph.D. Thesis, Mathura, Mathura, India, 2018.

43. Gjerde, B.; Luzón, M.; Alunda, J.M.; De La Fuente, C. Morphological and molecular characteristics of six Sarcocystis spp. from red deer (Cervus elaphus) in Spain, including Sarcocystis cervicanis and three new species. Parasitol. Res. 2017, 116, 2795-2811. [CrossRef]

44. Gazzonis, A.L.; Gjerde, B.; Villa, L.; Minazzi, S.; Zanzani, S.A.; Riccaboni, P.; Sironi, G.; Manfredi, M.T. Prevalence and molecular characterisation of Sarcocystis miescheriana and Sarcocystis suihominis in wild boars (Sus scrofa) in Italy. Parasitol. Res. 2019, 118, 1271-1287. [CrossRef]

45. Murata, R.; Suzuki, J.; Hyuga, A.; Shinkai, T.; Sadamasu, K. Molecular identification and characterization of Sarcocystis spp. in horsemeat and beef marketed in Japan. Parasite 2018, 25, 27. [CrossRef]

(C) 2020 by the authors. Licensee MDPI, Basel, Switzerland. This article is an open access article distributed under the terms and conditions of the Creative Commons Attribution (CC BY) license (http://creativecommons.org/licenses/by/4.0/). 